\title{
Laser-Plasma Deposition of Silicon Carbonitride Films by the HMDS Vapor Gas Flow Activation after a Laser Beam Focus
}

\author{
V. N. Demin ${ }^{*}$, V. O. Borisov, G. N. Grachev', A. L. Smirnov², M. N. Khomyakov², S. N. Bagayev² \\ ${ }^{1}$ Nikolaev Institute of Inorganic Chemistry, Siberian Branch of the Russian Academy of Sciences, Novosibirsk, Russia \\ ${ }^{2}$ Institute of Laser Physics, Siberian Branch of the Russian Academy of Sciences, Novosibirsk, Russia \\ Email: *demin@niic.nsc.ru
}

How to cite this paper: Demin, V.N., Borisov, V.O., Grachev, G.N., Smirnov, A.L., Khomyakov, M.N. and Bagayev, S.N. (2021) Laser-Plasma Deposition of Silicon Carbonitride Films by the HMDS Vapor Gas Flow Activation after a Laser Beam Focus. Advances in Materials Physics and Chemistry, 11, 121-130.

https://doi.org/10.4236/ampc.2021.117012

Received: June 4, 2021

Accepted: July 13, 2021

Published: July 16, 2021

Copyright $\odot 2021$ by author(s) and Scientific Research Publishing Inc. This work is licensed under the Creative Commons Attribution International License (CC BY 4.0).

http://creativecommons.org/licenses/by/4.0/

\begin{abstract}
A new laser-plasma deposition method has been developed for the plasma chemical deposition of hard silicon carbonitride coatings on stainless steel substrates from the hexamethyldisilazane (HMDS) $\mathrm{Si}_{2} \mathrm{NH}\left(\mathrm{CH}_{3}\right)_{6}$ vapor in a high-speed $\mathrm{Ar}$ and $\mathrm{Ar}+10$ vol.\% He gas stream at the HMDS gas flow activation after the laser beam focus. The method allows depositing silicon carbonitride coatings at the rate of $0.4-1.2 \mu \mathrm{m} \cdot \mathrm{min}^{-1}$, i.e. $\sim 2$ times higher than that at introducing HMDS in the laser beam focus zone. The properties of the prepared coatings have been studied by the methods of IR and Raman spectroscopy, atomic force microscopy, nanoindentation and X-ray diffraction (XRD) analysis. Studying the film structure with the use of XRD showed that the prepared silicon carbonitride coatings are X-ray amorphous. It has been found that the coating deposition rate and the structure of coatings depend on the process parameters: HMDS flow rate and plasma-generating gas (argon or $(\mathrm{Ar}+\mathrm{He})$. The method allows depositing SiCN films at a high speed and a hardness of $20-22 \mathrm{GPa}$.
\end{abstract}

\section{Keywords}

Laser-Plasma Deposition, Hard Coating, Silicon Carbonitride Films

\section{Introduction}

Laser plasma produced in a powerful optical pulsating discharge (POPD) in high-speed gas flows is a new form of optical discharge [1]. POPD is obtained in the gas under the impact of the laser pulse-periodic radiation of $10-120 \mathrm{kHz}$ and the laser pulse peak power of $500 \mathrm{~kW}$. In the plasma-chemical synthesis of 
coatings, the radiation is focused in high-speed gas fluxes of $100-300 \mathrm{~m} \cdot \mathrm{s}^{-1}$, providing a high gas phase cooling rate after the laser pulse, reduced size of the nucleation centers of solid-phase nuclei and a fast delivery of the decomposition products of reagents to the treated surface [2].

The synthesis of silicon carbonitride and carbon nitride films by the laser-plasma deposition in POPD plasma was used to grow hard protective films on stainless substrates by introducing precursor vapors in the laser beam focus [3] [4] [5] [6].

Silicon carbonitride is a unique multifunctional material, which successfully combines the best properties of silicon carbide and nitride. Silicon carbonitride layers are traditionally prepared either at increased temperatures $\left(\mathrm{T} \geq 1000^{\circ} \mathrm{C}\right)$ or by the chemical vapor deposition (CVD) at a relatively low temperature using high-frequency and microwave plasma or glow discharge plasma (PECVD) [7] [8] [9] [10] [11]. The formation of solid inorganic polymers of silicon carbonitride on silicon and quartz substrates at the laser pyrolysis of HMDS with ammonia additives was published earlier in [12].

Hexamethyldisilazane $\left(\mathrm{CH}_{3}\right)_{3} \mathrm{SiNHSi}\left(\mathrm{CH}_{3}\right)_{3}$ was chosen as a precursor because it contains all chemical fragments ( $\mathrm{Si}-\mathrm{N}, \mathrm{Si}-\mathrm{C})$ necessary for the formation of silicon carbonitride.

In this paper, we present the results of studying the kinetic and physicochemical properties of the silicon carbonitride films synthesized from the hexamethyldisilazane (HMDS) precursor by means of activation after the laser beam focus. The peculiarity of this plasma deposition variant is the effect of the action of argon plasma with a reduced energy due to its removal (taking out by the stream) from the laser beam focus. As a result of this interaction, the decomposition of the precursor molecule does not occur completely: only the organic component of the molecule is separated. Such fragments fall on the substrate, where their further chemical transformation takes place with the inorganic coating formation.

The addition of helium to a plasma-generating gas should not change the plasma parameters appreciably, since helium is introduced with a precursor after the laser beam focus, but it affects the growth kinetics and properties of coatings.

\section{Experimental Technique}

The films were deposited in the laser-plasma setup with a plasma-chemical chamber, which was reported on earlier in [3]. For the deposition, in contrast to [3], the precursor flux (HMDS + Ar) was introduced after the laser beam focus.

The film deposition was carried out onto stainless steel 304 substrates $(\mathrm{Cr} 20$; Mn 2; Ni 8; C $\leq 0.8$, wt.\%) (Figure 1).

The process parameters were as follows: the substrate temperature varied from $700^{\circ} \mathrm{C}$ to $800^{\circ} \mathrm{C}$ by the external heater, and the gas-carrier (argon) flux rate was $22-30 \mathrm{~L} / \mathrm{min}$. The average $\mathrm{t}$ laser beam power was $1.6 \mathrm{~kW}$, and the pulse repetition rate was $120 \mathrm{kHz}$. The mixture of liquid precursor was introduced in 


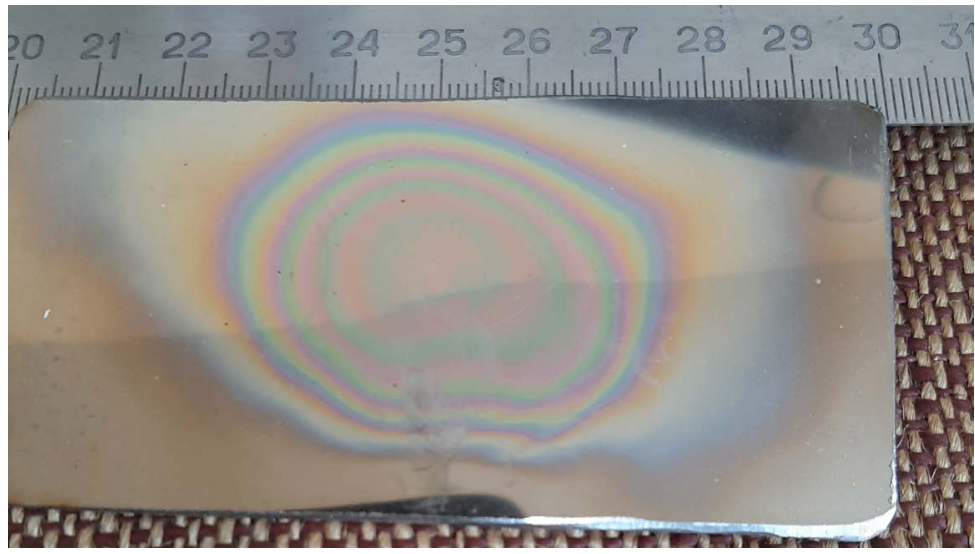

Figure 1. Photo of a stainless steel plate coated with SiCN film. $\mathrm{F}_{\mathrm{HMDS}}=30 \mu \mathrm{L} \cdot \mathrm{min}^{-1} \cdot \mathrm{F}_{\mathrm{Ar}}=$ $27 \mathrm{~L} \cdot \mathrm{min}^{-1}$.

the laser-plasma chemical reactor by a precision pump (Model LSP01) at the rate of $20-80 \mu \mathrm{L} \cdot \mathrm{min}^{-1}$ and then, by means of an argon or a $\mathrm{He}(3 \mathrm{~L} / \mathrm{min})$ flux, it was mixed with the main argon flux in the reactor $\left(22-27 \mathrm{~L} \cdot \mathrm{min}^{-1}\right)$. The deposition time was 1 - $3 \mathrm{~min}$. The deposition rate varied within $0.4-1.2 \mu \mathrm{m} \cdot \mathrm{min}^{-1}$ and depended on the process parameters. The coatings thickness was determined by the measurements of coatings reflection spectra and calculation on the known formulas, taking into account the refractive index determined from the ellipsometric data. To characterize the synthesized coatings, the following devices were used: Fourier IR spectrometer IFS-85 (Bruker), scanning electron microscope JSM 6700F with the EDS EX-23000 BU console, Raman Spectrometer LabRAM, Evolution, Horiba; Shimadzu XRD-7000, atomic-force microscope "Solver-Pro" (NT MDT) and scanning nanohardness meter NanoScan-3D (Technological Institute for Superhard and Novel Carbon Materials, Russia).

\section{Results and Discussion}

The laser-plasma deposition process is multiparametric, and its rate depends on such parameters as HMDS concentration in a gas flow, plasma-generating gas flux (consumption) and laser beam energy introduced in a gas flow.

The dependences of coating growth rates on the HMDS flux rates in the plasma-generating gas $\mathrm{Ar}$ and $\mathrm{Ar}+10$ vol.\% He are shown in Figure 2 .

It follows from Figure 2 that the growth rate dependence on the hexamethyldisilazane flux rate $\mathrm{F}_{\mathrm{HMDS}}$, at the HMDS gas flux activation after the laser beam focus, is higher (curves 2, 3) than that in the variant for introducing the precursor in the laser beam focus (curve 1). The growth rate dependence on the flow rate is nonmonotonic: it grows with the increase of $\mathrm{F}_{\mathrm{HMDS}}$ and reaches its maximum at $\mathrm{F}_{\mathrm{HMDS}} \approx 50 \mu \mathrm{L} \cdot \mathrm{min}^{-1}$, and then it goes down. This can be explained by the homogeneous nucleation of $\mathrm{SiCN}$ at this HMDS concentration in the gas phase, which then leads to the formation of a loose amorphous SiCN layer on the film edges [12]. The IR spectra of the coatings characterizing their chemical structure are given in Figure 3. In Figure 3 is the comparison of the IR spectra 


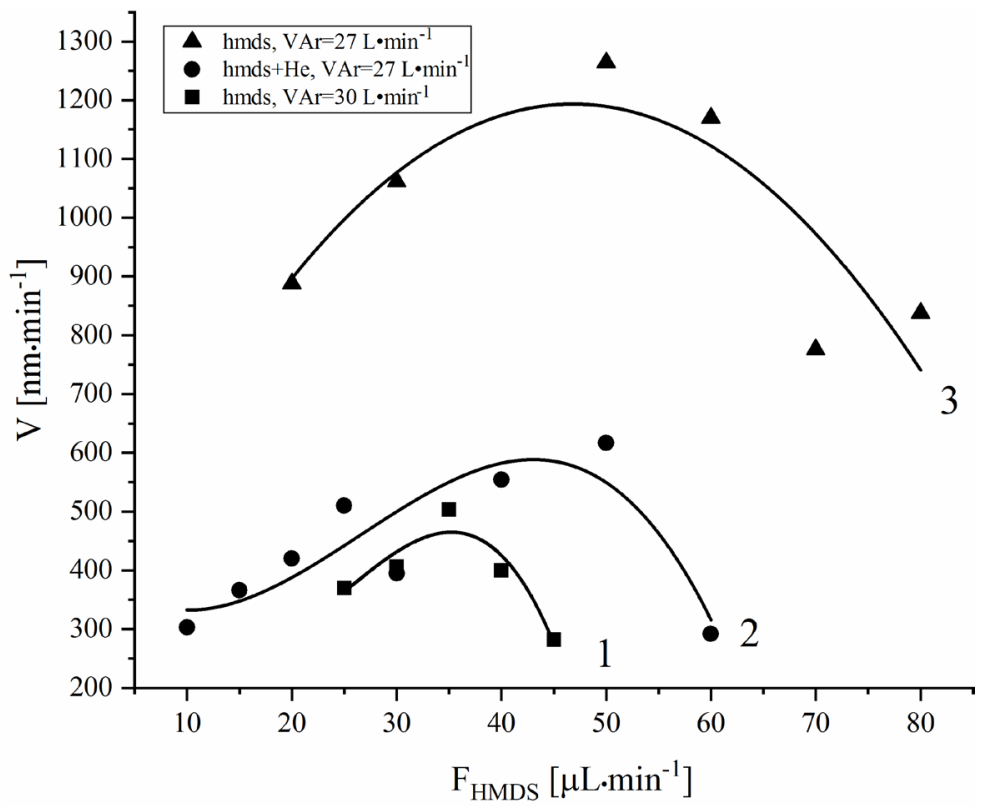

Figure 2. Dependences of coating growth rates on HMDS flux rates. 1-introduction of HMDS in the laser beam focus in the Ar flux of plasma-generating gas; 2-introduction of the HMDS gas flow after the laser beam focus in the $(\mathrm{Ar}+\mathrm{He})$ flux of plasma-generating gas; 3-introduction of the HMDS gas flow after the laser beam focus in the Ar flux of plasma-generating gas.
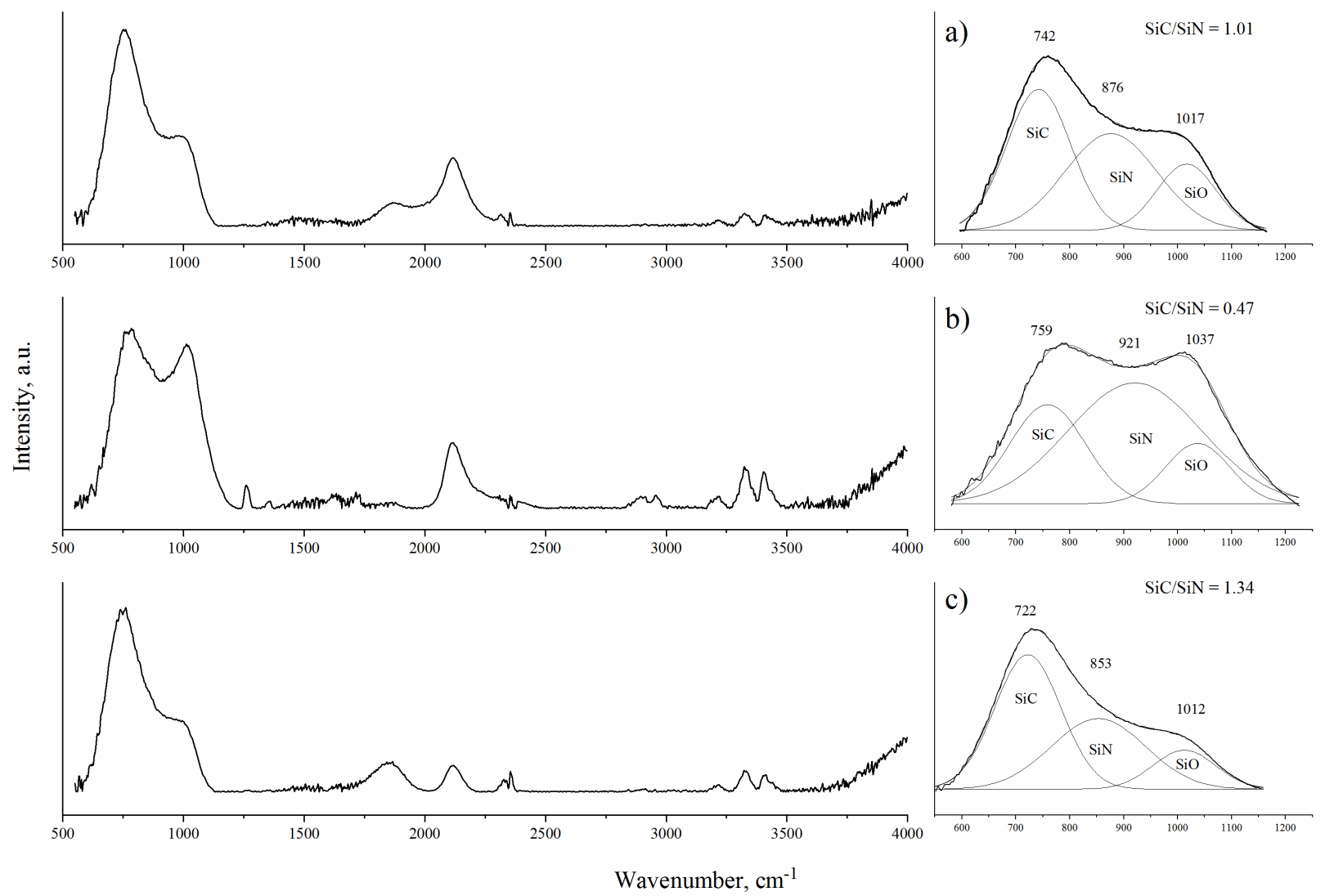

Figure 3. IR spectra of the coatings and Gaussian peak fitting: (a) Ar flux; (b) Ar +10 vol\% $\mathrm{He} \mathrm{F}_{\mathrm{HMDS}}=50 \mu \mathrm{L} \cdot \mathrm{min}^{-1}$; (c) introducing HMDS in the laser beam focus, Ar flux; $\mathrm{F}_{\mathrm{HMDS}}=35 \mu \mathrm{L} \cdot \mathrm{min}^{-1}$ and $\mathrm{F}_{\mathrm{Ar}}=27 \mathrm{~L} \cdot \mathrm{min}^{-1}$. 
of the films obtained from HMDS in the argon flux (Figure 3(a)) and those obtained in the $\left(\mathrm{Ar}+\mathrm{He}\right.$ ) flux (Figure $3(\mathrm{~b})$ ) at $\mathrm{F}_{\mathrm{HMDS}}=50 \mu \mathrm{L} \cdot \mathrm{min}^{-1}$ (maximum deposition rate). The IR deposition spectra at $\mathrm{F}_{\mathrm{HMDS}}=35 \mu \mathrm{L} \cdot \mathrm{min}^{-1}$ in the variant of introducing HMDS in the laser beam focus are given in Figure 3(c).

The decomposition of spectra $\mathrm{a}, \mathrm{b}$ and $\mathrm{c}$ into Gaussian components in the wavenumber region of $500-1500 \mathrm{~cm}^{-1}$ is also presented in Figure 3. When interpreting the absorption band decomposition results, we took into account that the peaks corresponding to the components are the superposition of different vibrational modes of the fragments forming the coatings.

The broad absorption bands decomposition of the spectrum in Figure 3(a) in the region of $500-1000 \mathrm{~cm}^{-1}$ shows three overlapping peaks at $742 \mathrm{~cm}^{-1}, 876$ $\mathrm{cm}^{-1}$ and $1017 \mathrm{~cm}^{-1}$.

There are main absorption bands corresponding to the oscillation modes of Si-C $\left(\omega=750 \mathrm{~cm}^{-1}\right)$, Si-N $\left(\omega=900 \mathrm{~cm}^{-1}\right)$ and $\mathrm{Si}-\mathrm{O}\left(\omega=1038 \mathrm{~cm}^{-1}\right)$ in the spectra. The spectra also show a small amount of bound hydrogen at $1250 \mathrm{~cm}^{-1}$ and $3200-3400 \mathrm{~cm}^{-1}$ (N-H bonds), and the Si-H bonds at $2200 \mathrm{~cm}^{-1}$, and that is associated with incompletely decomposed HMDS molecules [13]. The Si-C/Si-N ratio calculated from the IR spectra by the Gaussian peak fitting gives the values of 1.01 for (a), 0.47 for (b) and 1.34 for (c), respectively.

The Si-C/Si-N bonds ratio dependence, calculated from the IR spectra in the SiCN films produced at different HMDS supplies in the argon gas flux, is shown in Figure 4. The Si-C/Si-N ratio is increased from 0.4 to 1.6 by increasing the HMDS feeding rate from 20 to $70 \mu \mathrm{L} \cdot \mathrm{min}^{-1}$ in the $27 \mathrm{~L} \cdot \mathrm{min}^{-1}$ argon gas flux.

The coatings surface structure and morphology were determined using the

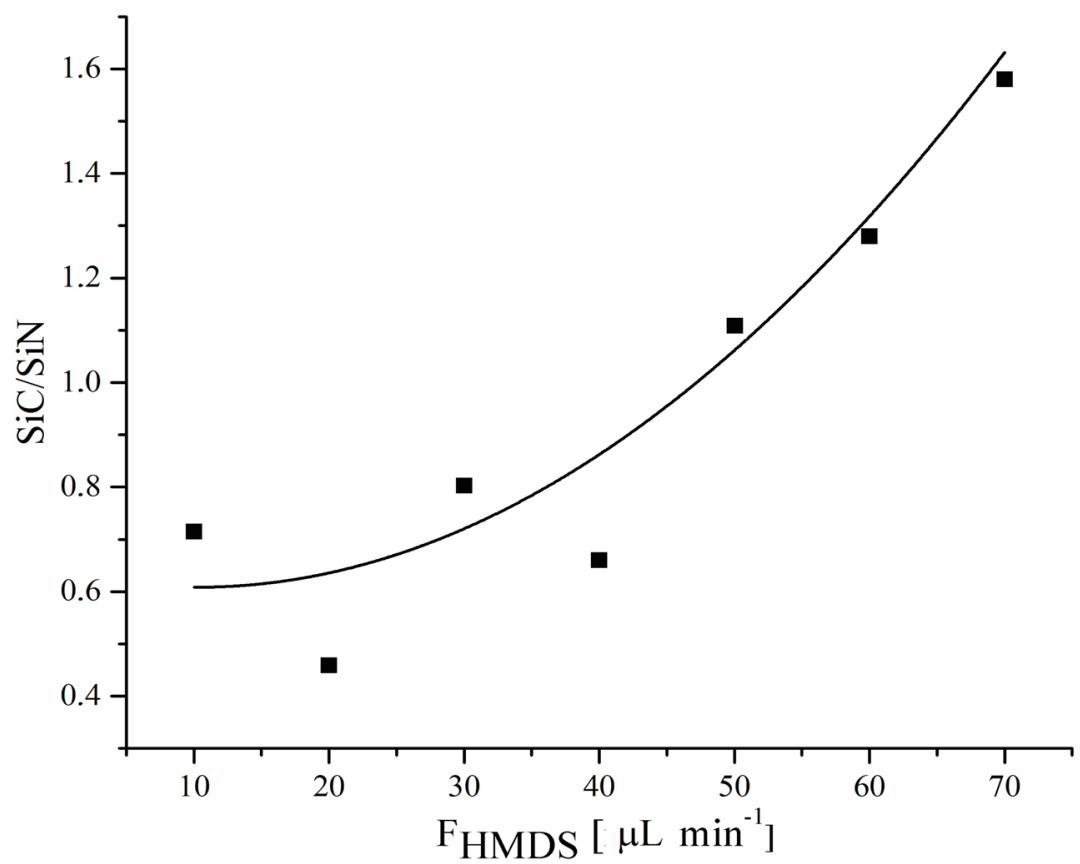

Figure 4. Si-C/Si-N bonds ratio dependence calculated from the IR spectra in the SiCN films produced at different HMDS feeding rates in the argon gas flux $\mathrm{F}_{\mathrm{Ar}}=27 \mathrm{~L} \cdot \mathrm{min}^{-1}$. 
X-ray diffraction analysis and atomic force microscopy. The X-ray diffraction data of the prepared films show that they are amorphous. The Raman spectra of the film obtained in the argon flux are given in Figure 5. There is a pike at 1427 $\mathrm{cm}^{-1}$, which is usually associated with disordered graphite [14] [15].

The EDS analysis of this film (Figure 6) gives the following concentration values of its elements (at.\%): $\mathrm{C}-38.60 ; \mathrm{N}-7.89 ; \mathrm{O}-14.8 ; \mathrm{Si}-38.72$.

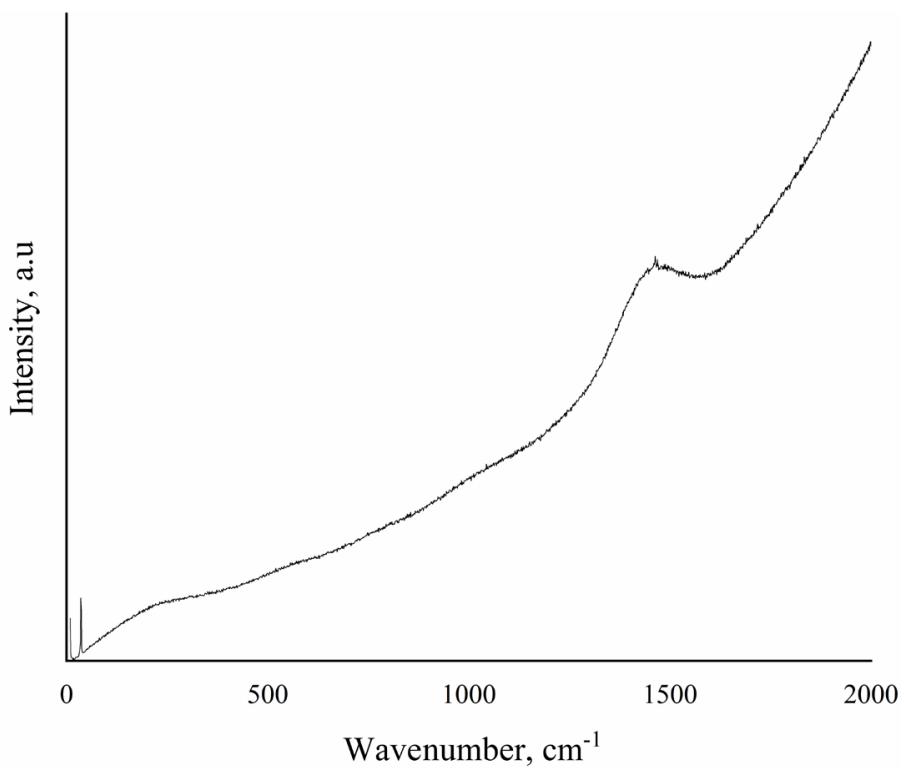

Figure 5. Raman spectrum of SiCN film; $\mathrm{F}_{\mathrm{HMDS}}=20 \mu \mathrm{L} \cdot \mathrm{min}^{-1}, \mathrm{FAr}=27 \mathrm{~L} \cdot \mathrm{min}^{-1}$.

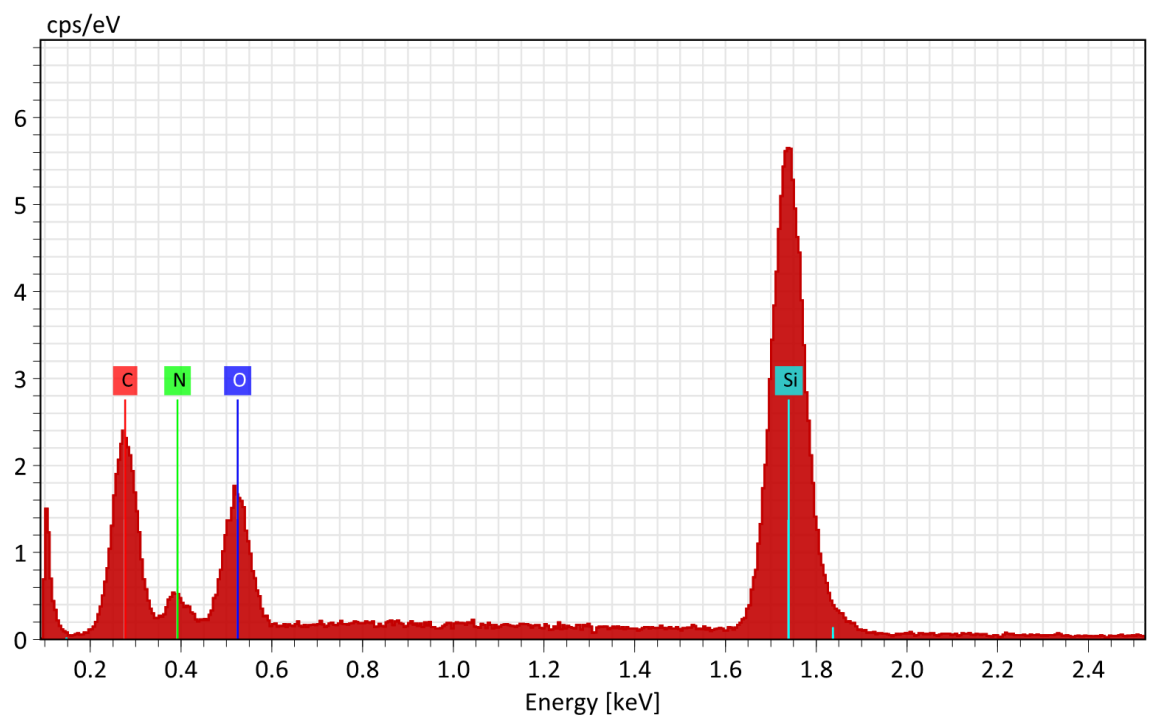

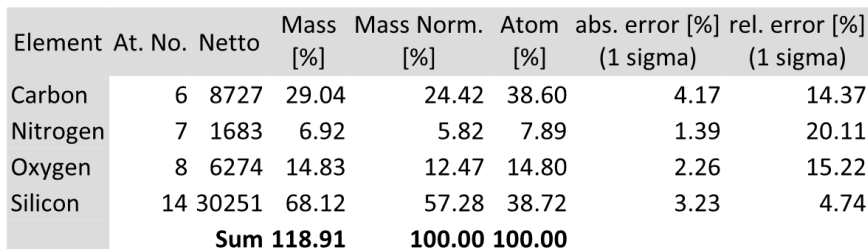

Figure 6. EDS analysis of the SiCN film. $\mathrm{F}_{\mathrm{HMDS}}=20 \mu \mathrm{L} \cdot \mathrm{min}^{-1}, \mathrm{FAr}=27 \mathrm{~L} \cdot \mathrm{min}^{-1}$. 
AFM image of SiCN films is shown in Figure 7.

The AFM study of morphology showed that, with an increase of feeding HMDS into the chamber, the film roughness and the average size of grains are increased.

The average surface grains size dependence on the rate of feeding HMDS into the chamber is shown in Figure 8.

As can be seen in the figure, the average size is increased from 0.11 to $0.20 \mu \mathrm{m}$ with the increase in the HMDS feeding rate from 20 to $80 \mu \mathrm{L} \cdot \mathrm{min}^{-1}$.

The AFM images of the coatings surface at different HMDS feeding rate values revealed that the roughness is changed from $21 \mathrm{~nm}$ to $66 \mathrm{~nm}$ with an increase in the HMDS feeding rate from 20 to $80 \mu \mathrm{L} \cdot \mathrm{min}^{-1}$.
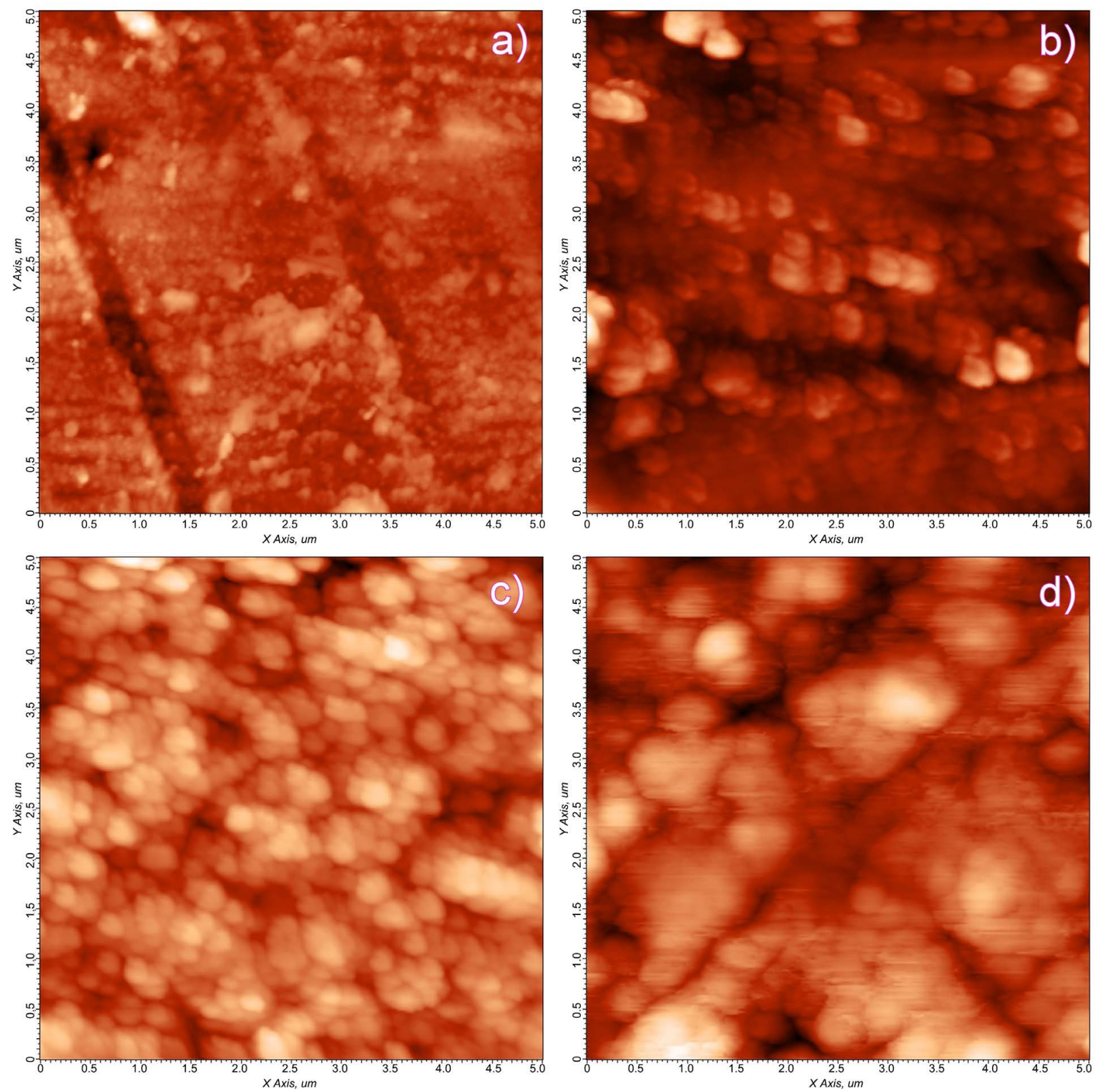

Figure 7. AFM image of deposited SiCN films. $\mathrm{F}_{\mathrm{Ar}}=27 \mathrm{~L} \cdot \mathrm{min}^{-1} ; \mathrm{F}_{\mathrm{HMDS}}=20$ (a); 50 (b); 60 (c); 80 (d) $\mu \mathrm{L} \cdot \mathrm{min}^{-1}$. 


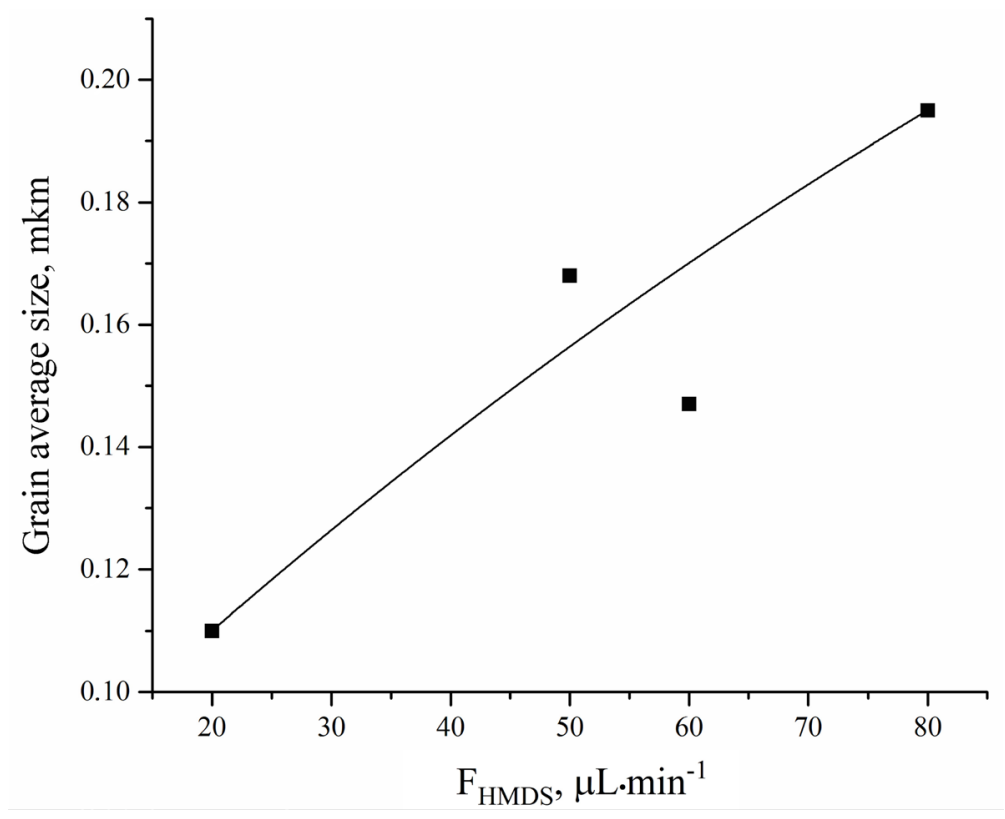

Figure 8. Average surface grains size dependence on the HMDS feeding rate.

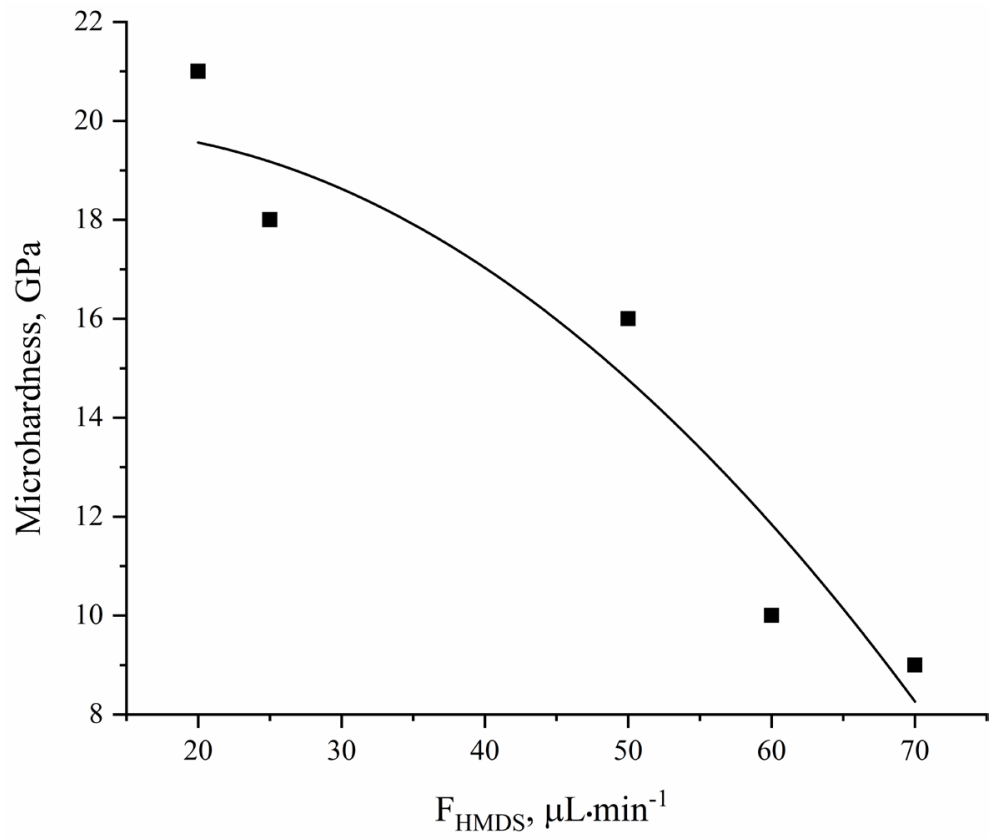

Figure 9. The SiCN film hardness dependence on the HMDS feeding rate $\left(\mathrm{F}_{\text {HMDS }}\right)$ in the argon gas flux $\left(27 \mathrm{~L} \cdot \mathrm{min}^{-1}\right)$.

The coatings hardness is determined by nanoindentation measurements (according to ISO 14577) with scanning nanohardometer NanoScan-3D. The measurements were performed at several loads from 1 to $50 \mathrm{mN}$. To determine the real hardness of the coating, with the influence of a softer substrate taken into account, the nanoindentation results were processed according to the techniques suggested in [16]. The dependence of SiCN film hardness on the HMDS feeding rate is given in Figure 9. 
The maximum hardness value was observed at the HMDS feeding rate of 25 $\mu \mathrm{L} \cdot \mathrm{min}^{-1}$. With an increase in the HMDS rate of feeding into the chamber, the hardness value is decreased, and it can be explained by the HMDS effect on plasma parameters and, due to this, the change in the kinetics of film deposition on a substrate.

\section{Conclusions}

A new laser-plasma deposition method has been developed for the deposition of hard protective silicon carbonitride coatings from hexamethyldisilazane (HMDS) $\mathrm{Si}_{2} \mathrm{NH}\left(\mathrm{CH}_{3}\right)_{6}$ vapors introduced, after the laser beam focus, in the high-speed $\mathrm{Ar}$ or $(\mathrm{Ar}+\mathrm{He})$ gas flux.

The method allows depositing silicon carbonitride coatings at the rate of 0.4 $1.2 \mu \mathrm{m} \cdot \mathrm{min}^{-1}$, i.e. $\sim 2$ times higher than that at introducing this precursor in the laser beam focus.

It has been found that the coating deposition rate and coatings structure depend on the process parameters: HMDS flow rates and plasma-generating gas $(\mathrm{Ar}$ or $(\mathrm{Ar}+\mathrm{He}))$.

The hardness of the produced films is $20-22 \mathrm{GPa}$ at FHMDS $=20-25$ $\mu \mathrm{L} \cdot \mathrm{min}^{-1}$, and it is decreased by an increase of feeding HMDS into the chamber.

\section{Conflicts of Interest}

The authors declare no conflicts of interest regarding the publication of this paper.

\section{References}

[1] Grachev, G.N., Ponomarenko, A.G., Smirnov, A.L., Tischenko, V.N. and Tret'jacov, P.K. (1996) Production of a Powerful Optical Pulsating Discharge (POPD) by $\mathrm{CO}_{2}$ Pulse-Periodic Laser Radiation in Supersonic Gas Flow. Laser Physics, 6, 376.

[2] Bagayev, S.N., Grachev, G.N., Ponomarenko, A.G., Smirnov, A.L., Demin, V.N., Okotrub, A.V., Baklanov, A.M. and Onischuk, A.A. (2007) A New Method of Laser-Plasma Synthesis of Nanomaterials: First Results and Prospects. SPIE Conference Proceedings, 2007, Article ID: 673206. https://doi.org/10.1117/12.751881

[3] Demin, V.N., Smirnova, T.P., Borisov, V.O., Grachev, G.N., Smirnov, A.L. and Khomyakov, M.N. (2015) The Laser Plasmochemical Synthesis of Hard Protective SiCN Films. Surface Engineering, 31,628-633. https://doi.org/10.1179/1743294414Y.0000000443

[4] Demin, V.N., Smirnova, T.P., Borisov, V.O., Grachev, G.N., Smirnov, A.L. and Khomyakov, M.N. (2015) Physical-Chemical Properties of Silicon Carbonitride Films Prepared Using Laser-Plasma Deposition from Hexamethyldisilazane. Glass Physics and Chemistry, 41, 232-236. https://doi.org/10.1134/S1087659615020042

[5] Demin, V.N., Smirnova, T.P., Borisov, V.O., Grachev, G.N., Smirnov, A.L. and Khomyakov, M.N. (2017) New Laser Plasma Process to Obtain Solid Coatings and Their Structural Characteristics. Journal of Structural Chemistry, 58, 1503-1509. https://doi.org/10.1134/S0022476617080042

[6] Demin, V.N., Smirnova, T.P., Borisov, V.O., Grachev, G.N., Smirnov, A.L. and Khomyakov, M.N. (2020) Deposition of Hard Silicon Carbonitride Coatings from 
Hexamethyldisilazane (HMDS) and HMDS + Benzene Vapours in Laser Plasma. Journal of Structural Chemistry, 61, 1390-1397. https://doi.org/10.1134/S002247662009005X

[7] Peterson, M., Berlind, T., Schmidt, S., Jacobson, S., Lhultman, Persson, C. and Engqvist, H. (2013) Structure and Composition of Silicon Carbon Nitride Coatings for Joint Replacements. Surface and Coatings Technology, 235, 827-834. https://doi.org/10.1016/j.surfcoat.2013.09.008

[8] Shi, Z.F., Wang, Y.J., Du, C., Huang, N., Wang, L. and Nung, C.Y. (2011) The Structure, Surface Topography and Mechanical Properties of Si-C-N Films Fabricated by RF and DC Magnetron Sputtering. Applied Surface Science, 258, 1328-1336. https://doi.org/10.1016/j.apsusc.2011.09.036

[9] Chen, Y.H., Yang, F.Q. and An, L.N. (2013) On Electric Conduction of Amorphous Silicon Carbonitride Derived from a Polymeric Precursor. Applied Physics Letters, 102, Article ID: 231902. https://doi.org/10.1063/1.4809825

[10] Liao, N.B., Hue, W., Zhou, H.M. and Zhang, M. (2013) Atomistic Investigation of Structural and Mechanical Properties of Silicon Csrbon Nitride with Different $\mathrm{SiC} / \mathrm{Si}_{3} \mathrm{~N}_{4}$ Ratios. Materials Chemistry and Physics, 143, 223-227. https://doi.org/10.1016/j.matchemphys.2013.08.055

[11] Riascos, H., Zambrano, G., Camps, E. and Prieto, P. (2007) Influence of Nitrogen gas Pressure on Plasma-Plume Chemical Bonding of Carbon Nitride Films Synthesized by Pulsed laser Deposition. Revista Mexicana De Fisica, 273-279

[12] Besling, W.F.A., Goosens, A., Meester, B., and Schoonman, J. (1998) Laser-Induced Chemical Vapor Deposition of Nanostructured Silicon Carbonitride Films. Journal of Applied Physics, 83, 544. https://doi.org/10.1063/1.366669

[13] Smirnova, T.P., Shainyan, B.A., Borisov, V.O. and Rakhlin V.I. ( 2007) Effect of the Chemical Structure of Silyl Derivatives of Unsymmetrical Dimethylhydrazine on the Composition and Structure of Silicon Carbonitride Films: Theoretical and Experimental Studies. Inorganic Materials, 43, 373-378. https://doi.org/10.1134/S0020168507040085

[14] Ferrari, A.C. and Robertson, J. (2001) Resonant Raman Spectroscopy of Disordered, Amorphous, and Diamond Like Carbon. Physical Review B, 64, Article ID: 075414. https://doi.org/10.1103/PhysRevB.64.075414

[15] Ferrari, A.C. and Robertson, J. (2000) Interpretation of Raman Spectra of Disordered and Amorphous Carbon. Physical Review B, 61, Article ID: 14095. https://doi.org/10.1103/PhysRevB.61.14095

[16] Korsunsky, A.M., McGurk, M.R., Bull, S.J. and Page, T.F. (1998) On the Hardness of Coated Systems. Surface and Coatings Technology, 99, 171-183. https://doi.org/10.1016/S0257-8972(97)00522-7 